\title{
Self-Pressurization and Spray Cooling Simulations of the Multipurpose Hydrogen Test Bed (MHTB) Ground-Based Experiment
}

\author{
O. Kartuzova and M. Kassemi \\ National Center for Space Exploration Research (NCSER) \\ J. Agui and J. Moder \\ NASA Glenn Research Center \\ Cleveland, $\mathrm{OH} 44135$
}

This paper presents a CFD model for simulating the self-pressurization of a large scale liquid hydrogen storage tank. In this model, the kinetics-based Schrage equation is used to account for the evaporative and condensing interfacial mass flows. Laminar and turbulent approaches to modeling natural convection in the tank and heat and mass transfer at the interface are compared. The flow, temperature, and interfacial mass fluxes predicted by these two approaches during tank self-pressurization are compared against each other. The ullage pressure and vapor temperature evolutions are also compared against experimental data obtained from the MHTB self-pressurization experiment. A CFD model for cooling cryogenic storage tanks by spraying cold liquid in the ullage is also presented. The EulerLagrange approach is utilized for tracking the spray droplets and for modeling interaction between the droplets and the continuous phase (ullage). The spray model is coupled with the VOF model by performing particle tracking in the ullage, removing particles from the ullage when they reach the interface, and then adding their contributions to the liquid. Dropletullage heat and mass transfer are modeled. The flow, temperature, and interfacial mass flux predicted by the model are presented. The ullage pressure is compared with experimental data obtained from the MHTB spray bar mixing experiment. The results of the models with only droplet/ullage heat transfer and with heat and mass transfer between the droplets and ullage are compared.

$\begin{array}{ll}\text { A } & =\text { Area density } \\ E & =\text { Energy } \\ \mathbf{g} & =\text { Gravity } \\ h & =\text { Surface curvature } \\ k & =\text { Turbulence kinetic energy } \\ L & =\text { Latent heat } \\ M & =\text { Molar mass of fluid } \\ n & =\text { Normal vector } \\ p, P & =\text { Pressure } \\ \mathbf{q} & =\text { Heat flux } \\ \dot{Q} & =\text { Heat power } \\ R & =\text { Gas constant } \\ T & =\text { Temperature } \\ t & =\text { Time } \\ \mathbf{v} & =\text { Velocity } \\ c_{p} & =\text { Heat capacity at constant pressure } \\ m & =\text { Mass }\end{array}$
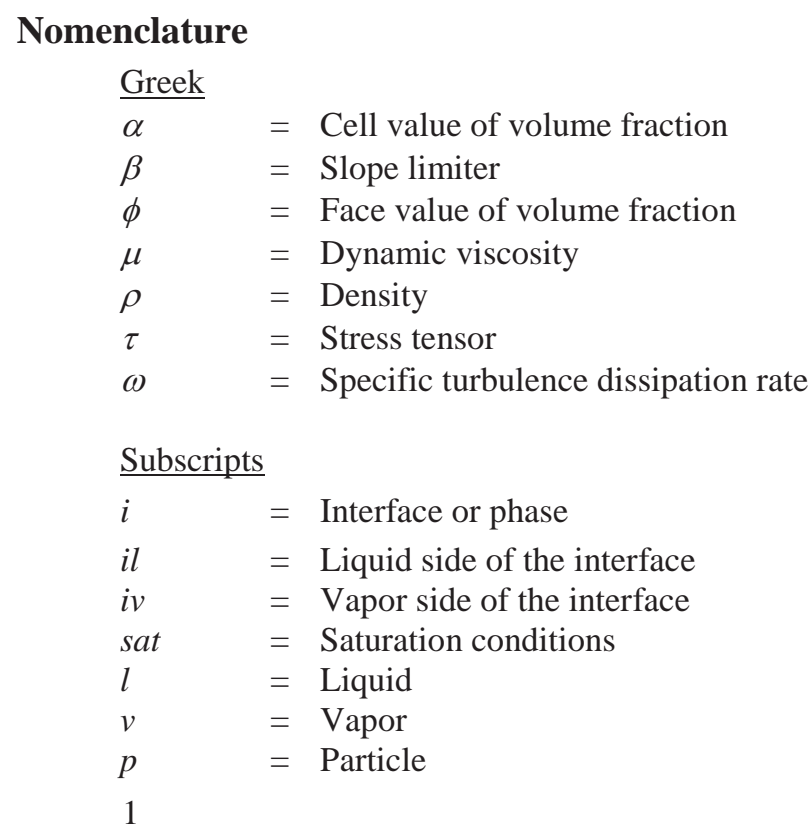

American Institute of Aeronautics and Astronautics 


\section{Introduction}

Efficient cryogenic fluid management of high energy propellants are in the critical path of nearly all the NASA future human exploration mission scenarios ${ }^{1}$. A key technology challenge is long duration storage of cryogens in space, where heat leaks through the insulation and various conduction paths cause tank selfpressurization. For short term operations, thrusters have traditionally been used to settle the propellant and relieve the tank pressure by venting. However, the added propellant and hardware weight (cost) to accommodate the increasing number of settling/venting sequences that becomes necessary in long duration missions will be quite prohibitive. Thus, maintaining tank pressure while minimizing the boil-off loss of propellants through an active pressure control mechanism has become a significant challenge associated with long term storage of cryogens in microgravity ${ }^{2}$.

Among various pressure control strategies that have been proposed and tested, the spray-bar thermodynamic vent system (TVS) has emerged as a promising mechanism that enables tank pressure control through venting without resettling. The key components of a TVS include a Joule-Thompson (J-T) expansion, a two-phase heat exchanger, and a spray-bar mixing pump system which, working together, enable destratification and extraction of heat from the tank with minimized liquid cryogen losses ${ }^{3}$ during pressure control. Unfortunately, implementation and optimization of the spray-bar TVS for future mission applications has been slow due to a lack of opportunities for on-orbit testing and technology demonstration. In order to partially alleviate this situation, it was decided to use comprehensive ground testing together with computational model development to aid the storage tank design. In this scheme, the numerical models will be validated with the ground-based pressurization and pressure control test results. Detailed microgravity simulation case studies for various mission applications can be performed with the validated numerical models. The simulation results can then be used to extrapolate and optimize the ground-tested spray-bar TVS design for successful microgravity operations.

To this end, in this paper, we will describe the development of a comprehensive two-phase CFD model for simulating the pressurization and pressure control of the Multipurpose Hydrogen Test Bed (MHTB) at NASA Marshall Space Flight Center (MSFC), as well as its validation by MHTB ground-based testing results. The 18- $\mathrm{m}^{3}$ $\left(693 \mathrm{ft}^{3}\right)$ storage tank employed in MHTB is representative in both size and shape of a fully integrated space transportation vehicle liquid hydrogen (LH2) propellant tank. The tank was designed to accommodate various components associated with different CFM concepts including a spray-bar TVS system ${ }^{3}$ for active pressure control and a multilayer Insulation (MLI) system for passive thermal isolation ${ }^{2}$.

Numerous numerical models with different degrees of sophistication have been developed to study storage tank operations in $1 \mathrm{~g}$ and/or microgravity ${ }^{4}$. However, many of these models have only studied tank selfpressurization ${ }^{5-7}$. Several have investigated tank pressure control, but mainly for applications where an axial forced jet is used to perform thermal destratification through liquid mixing ${ }^{8-11}$. In MHTB, storage tank pressure control is accomplished through the action of the longitudinal spray-bar TVS that provides simultaneous mixing and cooling in the liquid and droplet spraying in the ullage region. Comprehensive models of gas-droplet interaction have been developed for thermal management of electronic equipment, evaporative mist flow heat exchangers ${ }^{12}$, and combustion engines ${ }^{13-16}$. However, applications of such models to cryogenic storage tanks have been quite scarce and are limited to lumped models developed by NASA Marshall ${ }^{3}$ and Rockwell Aerospace ${ }^{17}$ and a Flow3D CFD model developed through a NASA-Boeing collaboration ${ }^{18}$. The latter predicted the experimental pressurization and pressure reduction trends well, but with an average 26\% under-prediction of experimental pressure rise and 50\% under-prediction of experimental pressure drop rates.

In the two-phase CFD model of the MHTB test tank presented in this paper, the Volume-of-Fluid (VOF) technique is used to capture the shape and evolution of the interface. A kinetic-based mass transfer submodel is employed to evaluate evaporative-condensing interfacial mass transfer. An Euler-Lagrange approach is utilized to track the spray droplets and capture the interaction between droplets and the continuous phase (vapor). By coupling the droplet and VOF models, it is possible to perform particle tracking in the vapor, removing particles from the vapor domain when they reach the interface and then adding their contributions to the liquid. To account for changes in tank pressure during the spraying cycle, an in-house droplet-ullage heat and mass transfer model is also developed. The kinetic-based Schrage equation is used to calculate the evaporative/condensing mass transfer from/to the droplet. Droplet temperature and size changes are calculated and tracked during the simulations and appropriate source terms are included in the governing equations to account for droplet-ullage mass, momentum, and energy transfer due to phase change.

In what follows, the important aspects of the mathematical model will be described first, and then the flow, temperature, and interfacial mass flux predicted by the model will be presented. Case studies are performed for the $50 \%$ and $90 \%$ fill levels and the predicted ullage pressure and temperatures are compared against their experimental 
MHTB counterpart for model validation. Simulation results for droplet/ullage heat transfer only and droplet/ullage with both heat and mass transfer are compared to underscore the important contribution of droplet vaporization/condensation to the evolution of tank pressure during the pressure control interval.

\section{Mathematical Model}

\section{A. Governing Equations}

The geometry and computational grid for the MHTB cryogenic storage tank partially filled with liquid hydrogen are shown in Fig. 2. This is a 2D axisymmetric grid that was used in the tank self-pressurization study. The grid is shown for a $50 \%$ tank fill ratio. A 3D $90^{\circ}$ sector grid, created from the $2 \mathrm{D}$ grid by revolving it along the tank centerline, was used to simulate spray cooling of the MHTB tank. Fluid flow and heat transfer in the tank are described in terms of the continuity, Navier-Stokes and energy equations for both phases:

$$
\begin{gathered}
\frac{\partial \rho}{\partial t}+\nabla(\rho \mathbf{v})=0 \\
\frac{\partial}{\partial t}(\rho \mathbf{v})+\nabla(\rho \mathbf{v} \mathbf{v})=-\nabla p+\nabla\left[\mu_{e f f}\left(\nabla \mathbf{v}+\nabla v^{T}\right)\right]+\rho \mathbf{g}+\mathbf{F}_{v o l}, \\
\frac{\partial}{\partial t}(\rho E)+\nabla(\mathbf{v}(\rho E+p))=\nabla\left(k_{e f f} \nabla T\right)+S_{h} .
\end{gathered}
$$

In the present study, the liquid phase is treated as incompressible with variable temperature-dependent properties, except for the density. The liquid density is allowed to vary linearly with temperature in the body force term of the momentum equation according to the Boussinesq approximation. The vapor is modeled as a compressible ideal gas. All the thermophysical and thermodynamic properties of the fluids are taken from the NIST Chemistry WebBook ${ }^{20}$ at saturation conditions.

In this study, the movement of the interface is captured diffusely using the Volume of Fluid (VOF) method, as promogulated by Hirt and Nichols ${ }^{21}$. Interfacial energy, momentum and mass balances are applied using source terms in the diffuse interfacial region.

\section{B. VOF Model}

In the VOF method, a volume fraction is defined in each cell such that the volume fractions of all the phases sum to unity. In the cell, the change in the interface can be tracked by solving a continuity equation for the volume fraction of the $q^{\text {th }}$ phase:

$$
\frac{1}{\rho_{q}}\left[\frac{\partial}{\partial t}\left(\alpha_{q} \rho_{q}\right)+\nabla \cdot\left(\alpha_{q} \rho_{q} \mathbf{v}_{q}\right)=S_{\alpha_{q}}\right]
$$

where the volume fraction for the primary phase is determined from:

$$
\sum_{q=1}^{n} \alpha_{q}=1
$$

In the VOF method, the field variables and properties are defined in terms of the volume fraction, which for a general system can be written as:

$$
\rho=\sum_{q=1}^{n} \alpha_{q} \rho_{q}, \quad \mu_{e f f}=\sum_{q=1}^{n} \alpha_{q} \mu_{e f f_{q^{\prime}}} \quad k_{e f f}=\sum_{q=1}^{n} \alpha_{q} k_{e f f_{q}} .
$$

In this fashion, the continuity, momentum and energy equations, as described by Eq. (1) - (3), can be solved throughout the domain for the temperatures and velocities in the two phases. In the VOF model, energy $(E)$ and temperature $(T)$ are treated as mass-averaged variables:

$$
E=\frac{\sum_{q=1}^{n} \alpha_{q} \rho_{q} E_{q}}{\sum_{q=1}^{n} \alpha_{q} \rho_{q}}
$$

where $E_{q}$ is based on the specific heat of the $q^{\text {th }}$ phase and the shared temperature.

Evaporation and condensation at the interface are modeled as a source term in the continuity equation for the volume fraction (Eq. 4), i.e.:

$$
S_{\alpha_{q}}=\dot{\mathbf{m}}_{i} \cdot \mathbf{A}_{i}
$$

where $\mathbf{A}_{i}$ is an interfacial area density vector, and $\dot{\mathbf{m}}_{i}$ is a mass flux vector, which for near equilibrium conditions can be determined based on the Schrage ${ }^{22}$ equation: 


$$
|\dot{\mathbf{m}}|=\left(\frac{2 \sigma}{2-\sigma}\right)\left(\frac{M}{2 \pi R}\right)^{1 / 2}\left(\frac{P_{i}}{T_{i}^{1 / 2}}-\frac{P_{v}}{T_{v}^{1 / 2}}\right) .
$$

Here $\sigma$ is the evaporation efficiency (a value of 0.001 was used in this study); $M$ is the molar mass of the fluid; $R$ is the universal gas constant; $P_{i}$ and $P_{v}$ are, respectively, the interfacial and vapor pressures (it was assumed that $P_{i} \cong$ $P_{\text {sat }}$ ); $T_{i}$ and $T_{v}$ are, respectively, the interfacial and vapor temperatures (it was assumed that $T_{i}=T_{v} \cong T_{\text {sat }}$ at the interface). Finally, $\mathbf{A}_{\mathbf{i}}$ is defined as:

where $\alpha$ is the volume fraction of the primary phase.

$$
\mathbf{A}_{i}=|\nabla \alpha|
$$

In the present implementation, the surface tension forces at the interface are modeled via the Continuum Surface Force (CSF) model of Brackbill et al. ${ }^{23}$. In this model, the surface tension forces at the interface are transformed into a volume force ( $\mathbf{F}_{v o l}$ ), which is added as a source to the momentum equation:

$$
\mathbf{F}_{\text {vol }}=\sum_{\text {pairs } i j, i<j} \sigma_{i j} \frac{\alpha_{i} \rho_{i} h_{i} \nabla \alpha_{j}+\alpha_{j} \rho_{j} h_{j} \nabla \alpha_{i}}{\frac{1}{2}\left(\rho_{i}+\rho_{j}\right)},
$$

where $h_{i}$ is the surface curvature calculated from the local gradients in the surface normal at the interface:

$$
h_{i}=\nabla \cdot \widehat{\mathbf{n}} .
$$

\section{Turbulence modeling}

In this study, the tank turbulence was modeled by utilizing the Shear Stress Transport $k-\omega$ model of Menter ${ }^{19}\left(\mathrm{kw}\right.$-SST). This model is similar to the standard $k$ - $\omega$ model of Wilcox ${ }^{24}$, but has the ability to account for the transport of the principal shear stress in adverse pressure gradient boundary layers. The model is based on the assumption of Bradshaw et al. ${ }^{25}$ that the principal shear stress is proportional to the turbulent kinetic energy, which is introduced into the definition of the eddy-viscosity. These features make the kw-SST model more accurate and reliable for a wider class of flows than the standard $k-\omega$ model $^{26}$.

In the VOF model, continuity of the turbulent quantities is inherently assumed since one set of equations for the turbulent kinetic energy and dissipation rate is solved for both phases throughout the domain, with properties varying according to the local volume fraction value.

\section{Lagrangian Spray model}

A customized Lagrangian Spray model of the ANSYS Fluent CFD code was utilized for simulating cooling of the MHTB tank by spraying cold liquid in a vapor region. This model uses the Euler-Lagrange approach, where the fluid phase (ullage) is treated as a continuum by solving the Navier-Stokes equations. The dispersed phase is solved by tracking a large number of particles (spray droplets) through the calculated flow field. The droplets exchange mass, momentum and energy with the fluid phase. In the Lagrangian spray model, the droplet trajectory is calculated by integrating the force balance on the droplet. This force balance equates the droplet inertia with the forces acting on the droplet as:

$$
\frac{d \vec{u}_{p}}{d t}=F_{D}\left(\vec{u}-\vec{u}_{p}\right)+\frac{\vec{g}\left(\rho_{p}-\rho\right)}{\rho_{p}}+\vec{F},
$$

where $\vec{u}$ is the fluid phase velocity, $\vec{u}_{p}$ is the particle velocity, $\rho$ is the fluid density, $\rho_{p}$ is the density of the droplet, $F_{D}$ is the drag force per unit droplet mass, and $\vec{F}$ is an additional acceleration. Integration of time in equation 13 yields the velocity of the droplet at each point along the droplet trajectory.

The spherical drag law proposed by Morsi and Alexander ${ }^{27}$ is applied for the droplet drag force calculation. The droplet energy equation is solved in the user subroutine as:

$$
m_{p} c_{p_{p}} \frac{d T_{p}}{d t}=h \cdot A_{p}\left(T_{\infty}-T_{p}\right)-L \dot{m}_{p}
$$

where $m_{p}$ is the droplet mass, $c_{p_{p}}$ is the heat capacity of the droplet, $A_{p}$ is the surface area of the droplet, $T_{\infty}$ is the local temperature of the continuous phase, $h$ is the convective heat transfer coefficient, $L$ is the latent heat, and $\dot{m}_{p}$ is the rate of evaporation/condensation on the droplet, obtained from the Schrage relation (equation 9) in $\mathrm{kg} / \mathrm{s}$.

The temperature of the droplet is obtained from equation 14 using correlation of Ranz and Marshall ${ }^{28,29}$ for evaluating the heat transfer coefficient: 


$$
N u=\frac{h d_{p}}{k_{\infty}}=2.0+0.6 \operatorname{Re}_{d}^{1 / 2} \operatorname{Pr}^{1 / 3},
$$

where $d_{p}$ is the droplet diameter, $k_{\infty}$ is the thermal conductivity of the continuous phase, $R e_{d}$ is the Reynolds number based on the particle diameter and the relative velocity, and $\operatorname{Pr}$ is the Prandtl number of the continuous phase.

The relative Reynolds number is calculated as:

$$
R e_{d} \equiv \frac{\rho d_{p}\left|\overrightarrow{u_{p}}-\vec{u}\right|}{\mu},
$$

where $\mu$ is the molecular viscosity of the fluid.

After the droplet energy equation is solved in the user subroutine, the mass, diameter and temperature of the droplets are updated. Mass, momentum and energy transfer between the droplets and continuous phase is modeled via source terms added to the equations 1-3. Source terms added to the momentum and continuity equations for the continuous phase are discussed in ANSYS Fluent theory guide ${ }^{26}$. Source term added to the energy equation of the continuous phase is discussed in the results section of this paper.

The Lagrangian Spray model is coupled with the VOF model via a user subroutine which performs particle tracking in the ullage, removes particles from the ullage when they reach the interface, and then adds their contributions to the liquid mass, momentum and energy equations through source terms (for those liquid cells near the location where the spray drops crossed the interface from vapor to liquid). Because the VOF method produces a diffuse interface, the criteria for determining when spray drops crossed into the bulk liquid was defined as the liquid drop entering a fluid cell with a liquid volume fraction $>0.1$.

\section{Numerical Implementation}

The interfacial mass transfer formulation used with the VOF scheme, droplet/ullage heat and mass transfer, and the coupling between the VOF and the Lagrangian Spray models have been developed, coded, and implemented into a customized in-house version of the ANSYS Fluent version 15.0 CFD code. In the VOF model, the interfacial mass transfer is calculated in the user subroutine, and sources are applied to the momentum and relevant scalar equations based on the assumption that mass "created" or "destroyed" will have the same momentum and energy of the phase from which it was "created" or "destroyed" 26 . All of the two-phase calculations are performed in the user subroutine, which is called once per outer iteration before any of the field equations are solved.

The computational domain for the $50 \%$ fill ratio case was discretized using an unstructured mesh of 9,246 cells, as depicted in Fig. 2. The computational grid for the $90 \%$ fill ratio case was created in a similar manner. In both the ullage and liquid regions, the conservation equations are evolved in time using a bounded second order time stepping routine with a time step size on the order of $5 \times 10^{-2}$ seconds for self-pressurization cases and $1 \times 10^{-4}$ seconds for spray cases. The second order monotone upwinding scheme is used to discretize the convective fluxes in the momentum, energy and turbulence equations. The PISO method is used for the pressure-velocity coupling.

For the volume fraction equation, the Compressive discretization scheme is used. The Compressive scheme is a second order reconstruction scheme for the VOF equation based on the slope limiter ${ }^{26}$. In this scheme:

$$
\phi_{f}=\phi_{d}+\beta \nabla \alpha_{d}
$$

where $\phi_{f}$ is the face value of volume fraction, $\phi_{d}$ is the donor cell value of volume fraction, $\beta$ is the slope limiter, and $\nabla \alpha_{d}$ is the donor cell volume fraction gradient.

In the Lagrangian spray cases, cold liquid enters the liquid phase as a "tiny jet" which is modeled as a source term defined in a user subroutine and added to the mass, energy and momentum equations in Fluent. Pressure control using spray bar TVS is simulated only for the $90 \%$ fill ratio case. In the $90 \%$ fill ratio case there are 38 liquid jets in the liquid region and 4 spray injections in the vapor region. Both liquid jets and spray injections have the same uniform temperature of $20.85 \mathrm{~K}$ and a liquid flow rate of $6.047 \mathrm{~kg} / \mathrm{s}$. The spray injection type is a plain orifice atomizer with four particle streams per injection. Two-way coupling between the droplets and continuous phase is enabled. In order to model heat and mass transfer between the droplets and ullage, first a value for the mass transfer rate is calculated in the subroutine. Then the droplet energy equation is solved, and the droplet temperature is updated. The mass and diameter of the droplet are updated to account for the amount of evaporated or condensed mass. Then, corresponding mass and energy sources are added to the ullage.

$1 \times 10^{-8}$.

Convergence criteria are set to $1 \times 10^{-5}$ for all equations except the energy equation, for which it is set to 


\section{Results and Discussion}

The case studies presented in this section are based on the MHTB tank self-pressurization and spray bar mixing experiments, which were conducted in normal gravity ${ }^{2}$. The MHTB tank consists of a cylindrical midsection with $3.05 \mathrm{~m}$ diameter and $3.05 \mathrm{~m}$ height and two 2:1 elliptical end caps. Two different tank liquid fill ratios (50\% and 90\%) are considered in the MHTB tank self-pressurization study. In the spray bar mixing study, only the $90 \%$ tank fill ratio is considered.

The gravitational vector is aligned with the tank's central axis in the negative axial direction. In the $90 \%$ fill ratio case, a uniform heat flux of $2.05 \mathrm{~W} / \mathrm{m}^{2}$ was applied at the tank wall to match the average wall heat flux of the experiment. In the $50 \%$ fill ratio case, a uniform heat flux of $0.89873 \mathrm{~W} / \mathrm{m}^{2}$ was applied at the wall in the vapor region, and $2.0841 \mathrm{~W} / \mathrm{m}^{2}$ in the liquid region. These values are based on previous thermal analysis and multinode simulations. Conduction through the tank wall was not considered. The spray bar assembly, which is approximated as lying along the tank centerline, is treated as an adiabatic surface. A zero velocity field is used as an initial condition for the self-pressurization simulations for both fill ratios. The initial turbulence conditions in the tank are set to uniform values of $\mathrm{k}=1 \times 10^{-6}, \mathrm{~m}^{2} / \mathrm{s}^{2}$; and $\omega=100,1 / \mathrm{s}$. The initial tank temperature is set to a uniform saturation value corresponding to the tank pressure in the $90 \%$ fill ratio case. In the $50 \%$ fill ratio case, an experimental tank temperature profile is applied as an initial condition for self-pressurization. The details of the selfpressurization cases are presented in Table 1. The temperature and velocity fields at the end of the selfpressurization case are transferred from 2D into 3D geometry, and used as initial conditions for the spray bar mixing case. The details of the spray bar mixing case are presented in Table 2. The initial tank pressure matched the experimental one for each case as given in Tables 1 and 2.

Table 1: Experimental conditions for tank self-pressurization tests

\begin{tabular}{ccccc}
\hline Case \# & Initial liquid fill, \% & Initial pressure, $\boldsymbol{k P a}$ & Final Pressure, $\boldsymbol{k P a}$ & Test Duration, hours \\
\hline $\mathbf{1}$ & 50 & 111.6 & 137.9 & 13.9 \\
$\mathbf{2}$ & 90 & 113.6 & 138.4 & 6.9 \\
\hline
\end{tabular}

Table 2: Experimental conditions for spray-bar mixing test

\begin{tabular}{ccccc}
\hline Case \# & Initial liquid fill, $\%$ & Initial pressure, $\boldsymbol{k P a}$ & Final Pressure, $\boldsymbol{k P a}$ & Test Duration, $\boldsymbol{s}$ \\
\hline $\mathbf{1}$ & 90 & 138.4 & 131.4 & 70 \\
\hline
\end{tabular}

A grid comparison study was performed for the $50 \%$ fill ratio self-pressurization case. The results for the tank pressure evolution from the three tested grids are presented and compared with experimental data in Fig. 1. The results for the interfacial mass transfer rate from three different grids are compared in Fig. 1 as well, but no experimental data on the interfacial mass transfer was available for comparison. All three grids have grid refinement near the wall and in the interfacial area. The coarse grid consists of 6,359 cells. The medium grid has 9,246 cells. It is similar to the coarse grid, but has more refinement in the interfacial area. It is shown in Fig. 2. The fine grid, which consists of 13,482 cells, is further refined at the interface as compared to the medium grid. All three grids predict very similar tank pressures and interfacial mass transfer rates. The fine grid simulation required 96 hours using 8 AMD Opteron ${ }^{\mathrm{TM}} 6100$ Series ("Magny-Cours") processors to complete 5000 seconds of self-pressurization. The medium grid simulation had approximately ten times shorter running time, compared with the fine grid. The coarse grid simulation was approximately twice as fast as the medium grid one. Simulations with the medium and coarse grids were run on the same number of processors as the fine grid simulation. Since the results of the selfpressurization study will be applied as initial conditions in the spray bar mixing study, where more refinement at the interface is beneficial, the medium grid, rather than the coarse one, was selected for this study. A grid with a similar level of refinement at the tank wall and at the interface was created and used for the $90 \%$ fill ratio self-pressurization cases.

Laminar and turbulent approaches were compared for modeling self-pressurization of the MHTB tank with a $50 \%$ tank fill ratio. In the turbulent case, the Shear Stress Transport $k-\omega$ model of Menter ${ }^{19}$ was used. The tank pressure and interfacial mass transfer rate evolutions from these two models are compared in Fig. 3 . The experimental tank pressure is also plotted in Fig. 3, but no experimental data on the interfacial mass transfer was available for comparison. The tank pressure predicted by the laminar VOF model is in excellent agreement with the experiment. This model predicts some evaporation (positive values of the mass transfer rate) at the interface for the first 1000 seconds of the tank self-pressurization period. It predicts condensation at the interface for the rest of the 
simulation time. The turbulent VOF model significantly under-predicts the experimental pressure, and predicts evaporation at the interface for the whole duration of tank self-pressurization. Temperatures along the vertical rake, located at $0.74168 \mathrm{~m}$ from the tank centerline, are compared at the end of the self-pressurization period from the laminar and turbulent VOF models and from the experiment in Fig. 4. The turbulent VOF model predicts much lower temperatures in the vapor and interfacial regions at the end of self-pressurization, compared to the laminar VOF model and experimental data. The laminar VOF model, although it somewhat over-predicts the experimental vapor temperatures, agrees with the experimental slope of the temperature distribution in the vapor and with the experimental temperatures near the interface. Temperatures and streamlines in the tank from the laminar and turbulent VOF models at the end of self-pressurization are compared in Fig. 5. The laminar VOF model predicts higher temperatures in the vapor and less mixing in both vapor and liquid at the end of the self-pressurization period, compared to the turbulent VOF model.

The laminar VOF model predicts higher tank pressure and vapor temperatures than the turbulent VOF model, despite the fact that the laminar model predicts vapor condensation at the interface during most of the tank self-pressurization period. Turbulent VOF model predicts evaporation throughout the self-pressurization period. This can be explained by the fact that the laminar VOF model predicts that less heat is transferred in the vapor region to the interface due to reduced mixing in the vapor. Thus, less heat is also transferred through the interface into the liquid region. The laminar VOF model predicts that more of the heat imparted by the wall stays in the vapor region, resulting in higher tank pressure and temperatures. In the turbulent VOF model, more heat is transferred to the interface due to increased turbulent mixing in the vapor. Thus, more heat also goes through the interface into the liquid. This leaves less heat in the vapor region and results in a lower tank pressure and vapor temperatures. In other words, in the turbulent VOF model, more heat is transferred through the interface into the liquid because the effective thermal conductivity (molecular plus turbulent) in this region is several orders of magnitude higher than its molecular counterpart in the laminar VOF case. This is shown in Fig. 6, where the effective thermal conductivity from the turbulent VOF case and the molecular thermal conductivity from the laminar VOF case are plotted along the interface at the end of tank self-pressurization.

Despite the fact that the natural convection flow inside the tank is in the turbulent regime (liquid $\mathrm{Ra}=$ $6.32 \times 10^{14}$; vapor $\mathrm{Ra}=1.83 \times 10^{13}$ ), the laminar VOF model seems to be better suited for modeling self-pressurization of the cryogenic storage tank in normal gravity. The turbulent VOF model implemented in the ANSYS Fluent CFD code under-predicts the MHTB tank pressure and vapor temperatures. This may be due to the fact that the turbulent damping effect of the interface is neglected in the turbulent VOF model, where continuity of turbulent quantities is assumed.

The MHTB tank self-pressurization study using the laminar and turbulent VOF models was repeated for the 90\% tank fill ratio case. The tank pressure and interfacial mass transfer rate evolutions from these two models are compared in Fig. 7. The experimental tank pressure is also plotted in Fig. 7, but no experimental data on the interfacial mass transfer was available for comparison. Similar to the $50 \%$ tank fill ratio cases, the turbulent VOF model significantly under-predicts the experimental pressure. The turbulent VOF model predicts initial condensation (negative values of the mass transfer rate) and evaporation at the interface after 8000 seconds of self-pressurization. The results of the laminar VOF model agree well with experimental pressures for the first 7000 seconds of selfpressurization. After 7000 seconds, and until the end of self-pressurization, the laminar VOF model somewhat overpredicts the experimental pressures. This model, just like in the $50 \%$ fill ratio case, predicts a short period of initial evaporation followed by condensation at the interface for most of the self-pressurization period. The difference in the laminar VOF model performance for the $90 \%$ fill ratio, compared to the $50 \%$ fill ratio case, can be explained by the fact that in the $90 \%$ fill ratio case, turbulence in the bulk liquid (which is not accounted for in the laminar VOF model) affects heat transfer in the tank more. In the 50\% fill ratio case, heat transfer in the tank is less affected by the turbulence in the bulk liquid because of the constraint imposed by the smaller volume of liquid.

The MHTB tank spray bar mixing simulation was performed for the $90 \%$ tank fill ratio case. The Shear Stress Transport $k-\omega$ turbulence model of Menter ${ }^{19}$ combined with the VOF model was used in this case. The tank pressure evolution from CFD is compared with experimental data in Fig. 8. The interfacial mass transfer rate evolution predicted in CFD is presented in Fig. 8, as well; however, no experimental data was available for comparison. The CFD spray model presented in Fig. 8 only includes heat transfer between droplets and ullage and assumes no droplet-ullage mass transfer. With this limitation, the CFD spray model predicts no pressure reduction in the tank for the first 50 seconds of spray cooling. After 50 seconds of spray cooling, this model predicts that the tank pressure begins to drop, but at a much slower rate than in the experiment. The CFD model predicts an initial increase in the evaporation rate at the interface, and reduced evaporation after the pressure in the tank starts to decrease. 
The CFD spray model without droplet-ullage mass transfer is not capable of predicting the correct rate of tank pressure reduction during spray cooling. Therefore it was necessary to develop and implement a model that includes both heat and mass transfer between droplets and ullage. The implementation and results of this model are discussed below. The Schrage relation (Eq. 9) was utilized to calculate the mass transfer rate between the droplet and ullage. Details of this model are presented in the Mathematical model section of this paper. As a first step in model implementation, a test study was performed in order to identify the correct mass and energy sources that are needed to couple the droplets and continuous phase (ullage) during mass transfer. In the test study, a simplified closed volume filled with compressible hydrogen vapor was considered. Two sides of the closed volume are square walls with 9 by 9 cells of orthogonal mesh. The extent of the domain is 10 times its height. The initial vapor temperature was set to a uniform value of $22 \mathrm{~K}$. In order to test the source terms added to the continuous phase during mass transfer, first two liquid hydrogen droplets were released at the center of the square wall and the simulation was run for 10 time steps. The initial temperature of the droplets at injection was set to $21 \mathrm{~K}$. The resulting vapor and droplet temperatures, vapor mass change and vapor energy sources are presented in Figures 9, 10 and 11, respectively. As shown in Fig. 9, the droplets only travelled through 2 computational cells during the simulation. After 10 time steps, the vapor temperature decreased in those cells that the droplets travelled through. This is due to the heat transfer between the hotter vapor and cooler droplets. The temperature of the droplets increased, as expected. Figure 10 shows that the vapor mass (monitored in Fluent) decreased during the simulation, which indicates vapor condensation on the droplets. The vapor mass source due to droplet/vapor mass transfer is implemented correctly if the vapor mass change matches the total amount of mass transfer from the droplets calculated in the user subroutine. This was tested, and the results are shown in Fig. 10. Here, the vapor mass change monitored in Fluent is compared with the total droplet mass change (with a negative sign) calculated in the user subroutine. The fact that the two results match indicates that the vapor mass source due to droplet/vapor mass transfer is implemented correctly.

According to the ANSYS Fluent Documentation ${ }^{26}$, the heat transfer from the continuous phase (vapor) to the discrete phase (droplet) is computed by examining the change in thermal energy of a droplet as it passes through each control volume, as:

$$
\begin{gathered}
Q=\frac{\dot{m}_{p, 0}}{m_{p, 0}}\left[\left(m_{p_{\text {in }}}-m_{p_{\text {out }}}\right)\left(-L_{\text {ref }}\right)-m_{p_{\text {out }}} \int_{T_{\text {ref }}}^{T_{p_{\text {out }}}} c_{p_{p}} d T+m_{p_{\text {in }}} \int_{T_{\text {ref }}}^{T_{p_{\text {in }}}} c_{p_{p}} d T\right], \text { or } \\
Q=\left[\frac{\dot{m}_{p, 0}}{m_{p, 0}}\left(m_{p_{\text {ln }}} \int_{T_{\text {ref }}}^{T_{p_{\text {ln }}}} c_{p_{p}} d T-m_{p_{\text {out }}} \int_{T_{\text {ref }}}^{T_{p_{\text {out }}}} c_{p_{p}} d T\right)\right]-\dot{m}_{p} L_{\text {ref }},
\end{gathered}
$$

where $\dot{m}_{p, 0}$ is the initial mass flow rate of the particle injection (kg/s); $m_{p, 0}$ is the initial mass of the particle $(\mathrm{kg})$; $m_{p_{\text {in }}}$ is the mass of the particle on cell entry (kg); $m_{p_{\text {out }}}$ is the mass of the particle on cell exit (kg); $c_{p_{p}}$ is the heat capacity of the particle $(\mathrm{J} /(\mathrm{kg} \cdot \mathrm{K}))$; $T_{p_{\text {in }}}$ is the temperature of the particle on cell entry (K); $T_{p_{\text {out }}}$ is the temperature of the particle on cell exit (K); $T_{r e f}$ is the reference temperature for the enthalpy equation (K); $L_{r e f}$ is the latent heat at reference conditions $(\mathrm{J} / \mathrm{kg})$.

The first part on the right hand side of Eq. 18 (in square brackets) is the correction for the particle mass source being added at a temperature other than the Fluent reference temperature. For simplicity, we will call this source "correction for the reference temperature". The second part on the right hand side of equation 18 is the energy source representing the latent heat addition. This source has to be added at the reference temperature. It is not clearly stated in ANSYS Fluent documentation what energy sources are added to the continuous phase internally if a mass source is added in a user subroutine. In order to investigate this issue, the sources presented in Eq. 18 are plotted in Fig. 11 for the duration of the spray test case. It is clearly seen that when only the latent heat addition source is added in the subroutine, the total source added in Fluent also includes the correction for the reference temperature part; therefore, there is no need to add this part in the subroutine.

To make sure that this model is also applicable for multiple droplets injected every time step and that it can be run for a longer time, the spray test case was rerun with two droplets injected every time step for 100 time steps. Vapor and droplet temperatures predicted in this case are presented in Fig. 12. Similar to the results of the previous test case shown in Fig. 9, here vapor is being cooled by the droplets and the droplets are being heated by the hotter vapor, as expected. Based on the analysis of the spray test cases presented above, the implementation of the droplet/ullage heat and mass transfer model is verified and can be applied to simulate the MHTB spray bar mixing experiment. 
The results of the MHTB spray bar mixing simulation with the droplet/ullage heat and mass transfer model are presented in Fig. 13. Here, the tank pressure evolutions are compared between the two models, with and without droplet/ullage mass transfer, and the model results are also compared with experimental data. The interfacial mass transfer rate evolutions predicted by the two models are compared in Fig. 13, as well; however, no experimental data was available for comparison. The model with droplet/ullage heat and mass transfer predicts a tank pressure drop during spray cooling that compares well with experimental data for the first 25 seconds of the simulation. After 25 seconds of spray, this model somewhat over-predicts the rate of the pressure drop in the tank. The model with only heat transfer between the droplets and ullage predicts no pressure reduction in the tank for the first 50 seconds of spray, which disagrees with the experiment and the model with droplet/ullage heat and mass transfer. The model with heat and mass transfer between droplets and ullage predicts less evaporation at the interface compared with the model that only includes heat transfer. This is because, in the model with only heat transfer modeled between the droplets and ullage, the vapor is not cooled by evaporating droplets, and hotter vapor at the interface results in more evaporation than in the case with droplet/ullage heat and mass transfer. This is illustrated in Fig. 14, where temperature and velocity fields at the mid-plane section of the tank predicted by the two models are shown after 50 seconds of spray. In the experiment the spray is on for 70 seconds, but significant tank pressure reduction is already achieved at 50 seconds of spray. Droplet distributions from the two models colored by droplet temperatures are shown in Fig. 14, as well. Higher droplet temperatures and higher temperatures in the ullage are observed in the case with no droplet/ullage mass transfer. In the case with droplet/ullage mass transfer, evaporating droplets cool down the ullage. This case results in lower droplet and ullage temperatures than the case without droplet/ullage mass transfer. Evaporating droplets lose their mass and momentum, and do not travel through the vapor as far as the droplets that do not evaporate, as can be seen from the velocity vectors shown in Fig. 14.

A droplet/ullage heat and mass transfer model was developed and implemented with Lagrangian spray and the VOF models of ANSYS Fluent commercial CFD code. This model was utilized for simulating the MHTB spray bar mixing experiment. The model with droplet/ullage mass transfer predicted a pressure drop in the tank that matched the experimental one. The CFD spray model without droplet/ullage mass transfer predicted a delayed pressure reduction in the tank and a slower pressure reduction afterward, compared to the experimental data. This is due to a larger amount of heat transferred by the droplets to the interface, which resulted in a high evaporation rate. It is necessary to include droplet-ullage mass transfer into a CFD model in order to accurately predict the spray cooling of cryogenic storage tanks.

\section{Conclusion}

A two-phase CFD compressible VOF model for the self-pressurization and pressure control inside the cryogenic storage tanks was presented. Two different tank fill ratios, $50 \%$ and $90 \%$, were considered. The laminar and turbulent approaches to modeling the liquid, ullage, and interfacial regions were compared. The model was validated against the experimental data provided from the MHTB self-pressurization and spray bar mixing experiments. Simulation results for droplet/ullage heat transfer only and droplet/ullage with both heat and mass transfer were presented and compared to underscore the important contribution of droplet vaporization/condensation to the evolution of tank pressure during the pressure control interval.

In the case of the tank self-pressurization the laminar VOF model resulted in tank pressures and temperatures that agree well with the experimental ones for the whole duration of simulation in the $50 \%$ tank fill ratio case. In the $90 \%$ tank fill ratio case, the tank pressure predicted by the laminar VOF model agreed well with the experiment for the first 7000 seconds of self-pressurization. This model predicted higher than experimental tank pressure for the rest of the self-pressurization period. The turbulent VOF model significantly under-predicted the tank pressure and temperatures in the ullage compared to the experimental data. This is due to excessive mixing in the ullage and over-prediction of the amount of heat transfer through the interface produced by this model.

A CFD model for cooling of cryogenic storage tanks by spraying cold liquid in the vapor region was developed, and its results were presented. The Euler-Lagrange approach implemented in the spray model of the ANSYS Fluent CFD code was utilized for tracking the spray droplets, and for modeling the interaction between the droplets and the continuous phase (ullage). The spray model was coupled with the VOF model via a user subroutine which performs particle tracking in the vapor, removes particles from the vapor domain when they reach the interface, and then adds their contributions to the liquid through source terms. Two different versions of this model were compared. The first version included only heat transfer between the droplets and ullage. This version is part of the ANSYS Fluent code. In this version, a delay was predicted in the tank pressure reduction during spray cooling as compared to the experiment for the first 50 seconds of spray, and the tank pressure decreased slower than in experiment for the rest of the simulation. This is due to a large amount of heat transferred by the droplets to the 
interface, which resulted in a higher evaporation rate. In the second version, a model for mass transfer interaction between droplet and ullage due to droplet phase change was developed and incorporated into Fluent via a user subroutine. The model with droplet/ullage heat and mass transfer resulted in a more accurate prediction of the tank pressure decrease during spray cooling of the cryogenic storage tank. This model also predicted a lower amount of heat transferred by the droplets to the interface, which resulted in a lower evaporation rate than predicted by the model with only droplet/ullage heat transfer.

The results of this study show that it is important to include the droplet/ullage heat and mass transfer when simulating active cooling of cryogenic storage tanks using spray.

\section{Acknowledgments}

This work was supported by NASA's Technology Demonstration Missions Program under the Cryogenic Propellant Storage and Transfer Project.

\section{References}

${ }^{1}$ Salzman, J., "Fluid management in space-based systems," Proceedings of the Engineering, Construction, and Operations in Space, 5th international conference on space, Vol. 1, 1996, p. 521-6.

${ }^{2}$ Martin, J.; and Hastings, L.: "Large-Scale Liquid Hydrogen Testing of a Variable Density Multilayer Insulation with a Foam Substrate,” NASA/TM-2001-211089, Marshall Space Flight Center, AL, June 2001.

${ }^{3}$ Hastings, L.J., Flachbart, R.H., Martin, J.J., Hedayat, A., Fazah, M., Lak, T., Nguyen, H., Bailey J.W. "Spray Bar ZeroGravity Vent System for On-Orbit Liquid Hydrogen Storage” NASA TM-212926, 2003.

${ }^{4}$ Barsi S. and Kassemi, M. "Investigation of Tank Pressurization and Pressure Control-Part II: Numerical Modelling", ASME Journal of Thermal Science \& Engineering Applications, Vol. 5, No 2, pp- 041006: 1-9, December 2013

${ }^{5}$ Kartuzova, O., Kassemi M., "Modeling Interfacial Turbulent Heat Transfer during Ventless Pressurization of a Large Scale Cryogenic Storage Tank in Microgravity," AIAA 47 Joint Propulsion Conference, AIAA, San Diego, CA, 2011

${ }^{6}$ Grayson, G.D., Lopez, A., Chandler, F.O., Hastings L.J., Tucker, S.P., "Cryogenic Tank Modeling for the Saturn AS-203 Experiment," Proceedings of the 42 ${ }^{\text {nd }}$ AIAA/ASME/SAE/ASEE Joint Propulsion Conference, AIAA 2006-5258, 2006.

${ }^{7}$ S. Barsi, M. Kassemi, "Numerical and Experimental Comparisons of the Self-Pressurization Behavior of an LH2 Tank in Normal Gravity”, Cryogenics, 48(3/4), pp. 122-129, 2007.

${ }^{8}$ Kartuzova, O., Kassemi M., "Modeling Active Pressure Control in a Large Scale Cryogenic Storage Tank in Normal Gravity," AIAA 48 $8^{\text {th }}$ Joint Propulsion Conference, AIAA, Atlanta, GA, 2012

${ }^{9}$ C.H. Panzarella and M. Kassemi, Comparison of Several Zero-Boil-Off Pressure Control Strategies for Cryogenic Storage in Microgravity, Journal of Power \& Propulsion, Vol. 25, No. 2, pp. 424-434, 2009.

${ }^{10}$ C. H. Panzarella, M. Kassemi, Pressure Control of Large Cryogenic Tanks in Microgravity, Cryogenics, Vol. 44/6-8, pp. 475-483, 2004.

${ }^{11}$ C.H. Panzarella, and M. Kassemi, On the Validity of Purely Thermodynamic Description of Two-Phase Cryogenic Storage Tank, Journal of Fluid Mechanics, Vol 484, pp.136-148, 2003.

${ }^{12}$ Kumari, N. Bahadur, V., Hode, M., Salamon, T., Kolodner, P, Lyons, A., Garimella, S. V., “Analysis of evaporating mist flow for enhanced convective heat transfer", International Journal of Heat and Mass Transfer 53 (2010) 3346-3356.

${ }^{13}$ Sirignano, W.A., "Fluid Dynamics of Sprays," Journal of Fluids Engineering, Vol. 115, no. 3, pp. 345-378, September 1993.

${ }^{14}$ Crowe, C.T., Sharma, M.P., and Stock, D.E., "The Particle-Source-in Cell (PSI-CELL) Model for Gas-Droplet Flows”, J. Fluids Eng., Vol. 99, pp. 325, 1977.

${ }^{15}$ Raju, M.S., and Sirignano, W.A., "Spray Computations in a Centerbody Combustor" Journal of Engineering for Gas Turbines and Power, Vol. 1, No. 4, pp. 710-718, October 1989.

${ }^{16}$ Raju, M.S., "Current Status of the Use of Parallel Computing in Turbulent Reacting Flows, Computations Involving Sprays, Scalar Monte Carlo Probability Density Function \& Unstructured Grids”, Advances in Numerical Heat Transfer, Vol. 2, ch. 8, pp.259-287, 2000.

${ }^{17}$ Nguyen, H.: Zero-G “Thermodynamic Venting System (TVS) Performance Prediction Program”, Rockwell Aerospace, Contract NAS8-39202, May 24, 1994

${ }^{18}$ Grayson et al, "CFD Modeling of Helium Pressurant Effects on Cryogenic Tank Pressure Rise Rates in Normal Gravity", AIAA 2007-5524, 43rd AIAA/ASME/SAE/ASEE Joint Propulsion Conference \& Exhibit - 11 July 2007, Cincinnati, OH,

${ }^{19}$ Menter, F. R., "Two-Equation Eddy-Viscosity Turbulence Models for Engineering Applications," AIAA Journal, Vol. 32 No. 8, 1994, pp. 1598-1605

${ }^{20}$ Lemmon, E.W., McLinden, M.O., and Friend, D.G., "Thermophysical Properties of Fluid Systems" in NIST Chemistry WebBook, NIST Standard Reference Database Number 69, Eds. Linstrom, P.J., and Mallard, W.G., National Institute of Standards and Technology, Gaithersburg MD, 20899, http://webbook.nist.gov.

${ }^{21}$ Hirt, C.W., and Nichols B.D., "Volume of fluid (VOF) method for the dynamics of free boundaries," Journal of Computational Physics, Vol. 39 No. 1, 1981, pp. 201-225.

${ }^{22}$ Schrage, R.W., A theoretical study of interphase mass transfer, Columbia University Press, New York, 1953. 
${ }^{23}$ Brackbill J.U., Kothe, D.B., Zemach, C., “A continuum method for modeling surface tension,” J. Comp. Phys. Vol. 100, 1992, pp. 335-354.

${ }^{24}$ Wilcox, D.C., Turbulent Modeling for CFD, DCW Industries, Inc., La Canada, California, 1998

${ }^{25}$ Bradshaw, P., Ferriss, D.H., and Atwell, N.P., "Calculation of Boundary-Layer Development Using the Turbulent Energy Equation," Journal of Fluid Mechanics, Vol. 28, No. 3, 1967, pp. 593-616.

${ }^{26}$ ANSYS Fluent Documentation. Release 15.0. November 2013.

${ }^{27}$ S. Morsi, A. and Alexander, A. J. "An Investigation of Particle Trajectories in Two-Phase Flow Systems," Journal of Fluid Mechanics, Vol. 55, No. 2, 1972, pp. 193-208.

${ }^{28}$ Ranz, W. E. and Marshall, W. R., Jr. "Evaporation from Drops, Part I," Chemical Engineering Progress, Vol. 48, No. 3, 1952, pp. 141-146.

${ }^{29}$ Ranz, W. E. and Marshall, W. R., Jr. "Evaporation from Drops, Part II," Chemical Engineering Progress, Vol. 48, No. 4, 1952, pp. 173-180. 


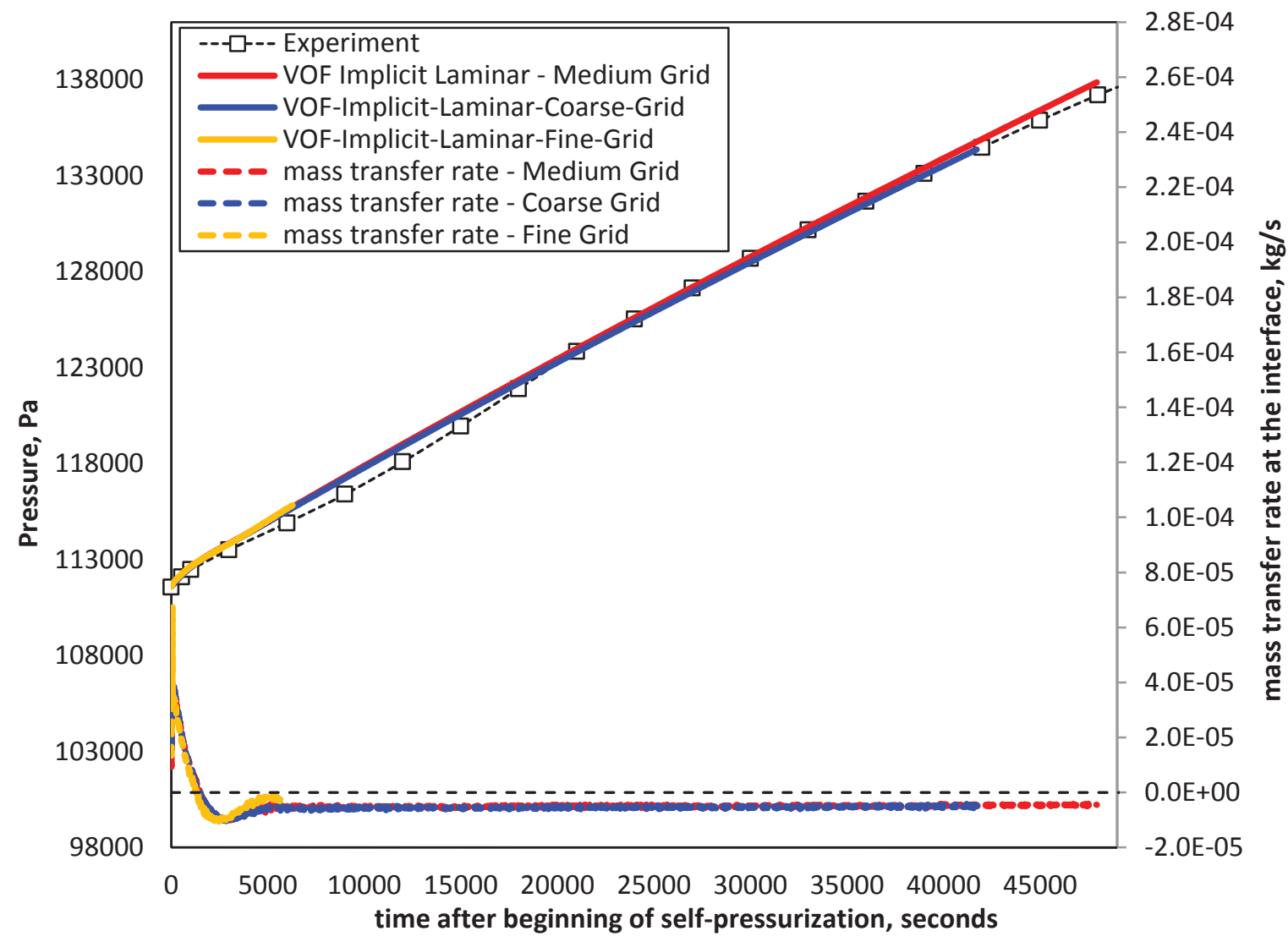

Figure 1: Pressure and interfacial mass transfer rate (positive for evaporation) evolutions during self-pressurization of MHTB tank (50\% fill ratio): Grid Comparison

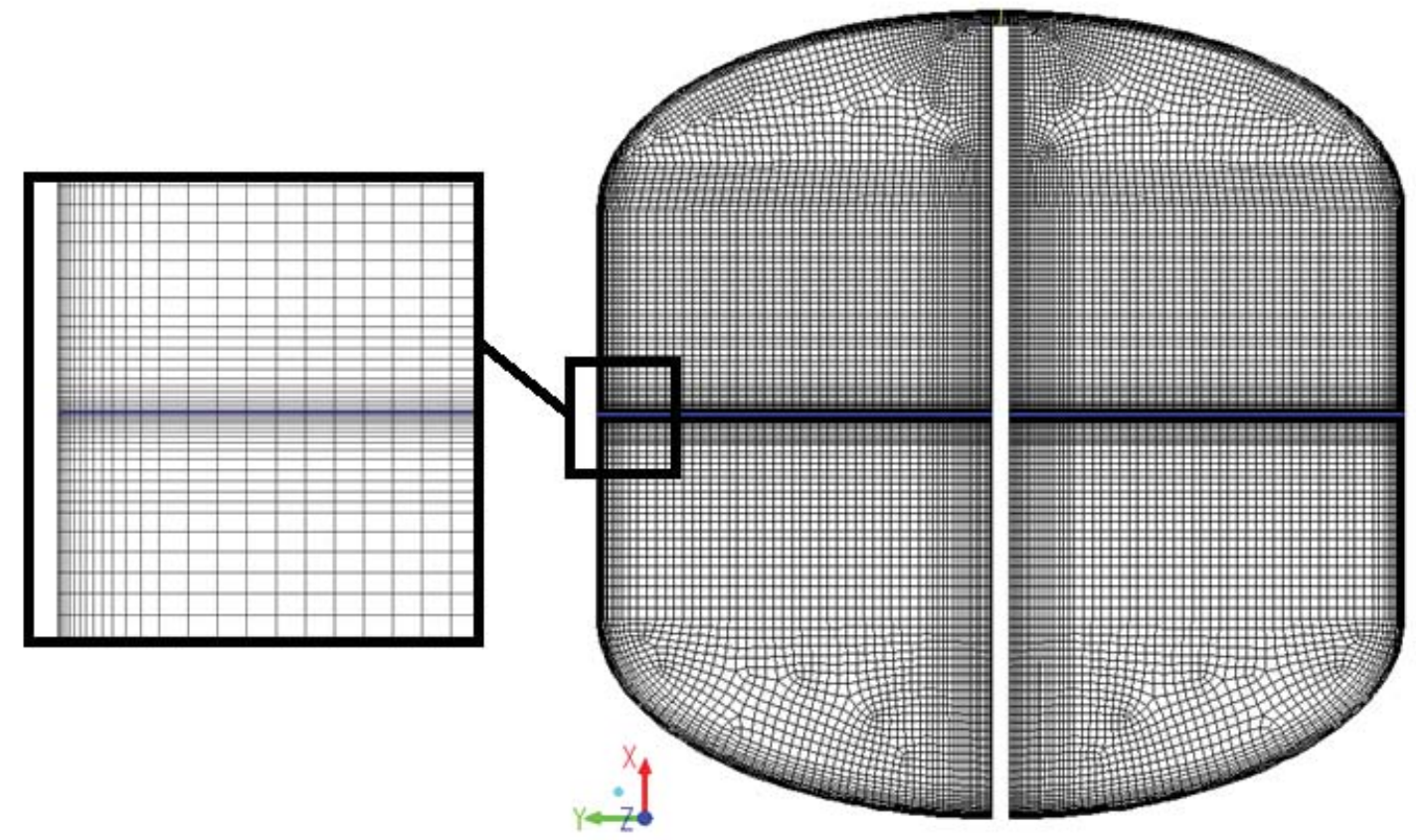

Figure 2: Medium grid used for the 50\% fill ratio cases (9,246 cells)

American Institute of Aeronautics and Astronautics 


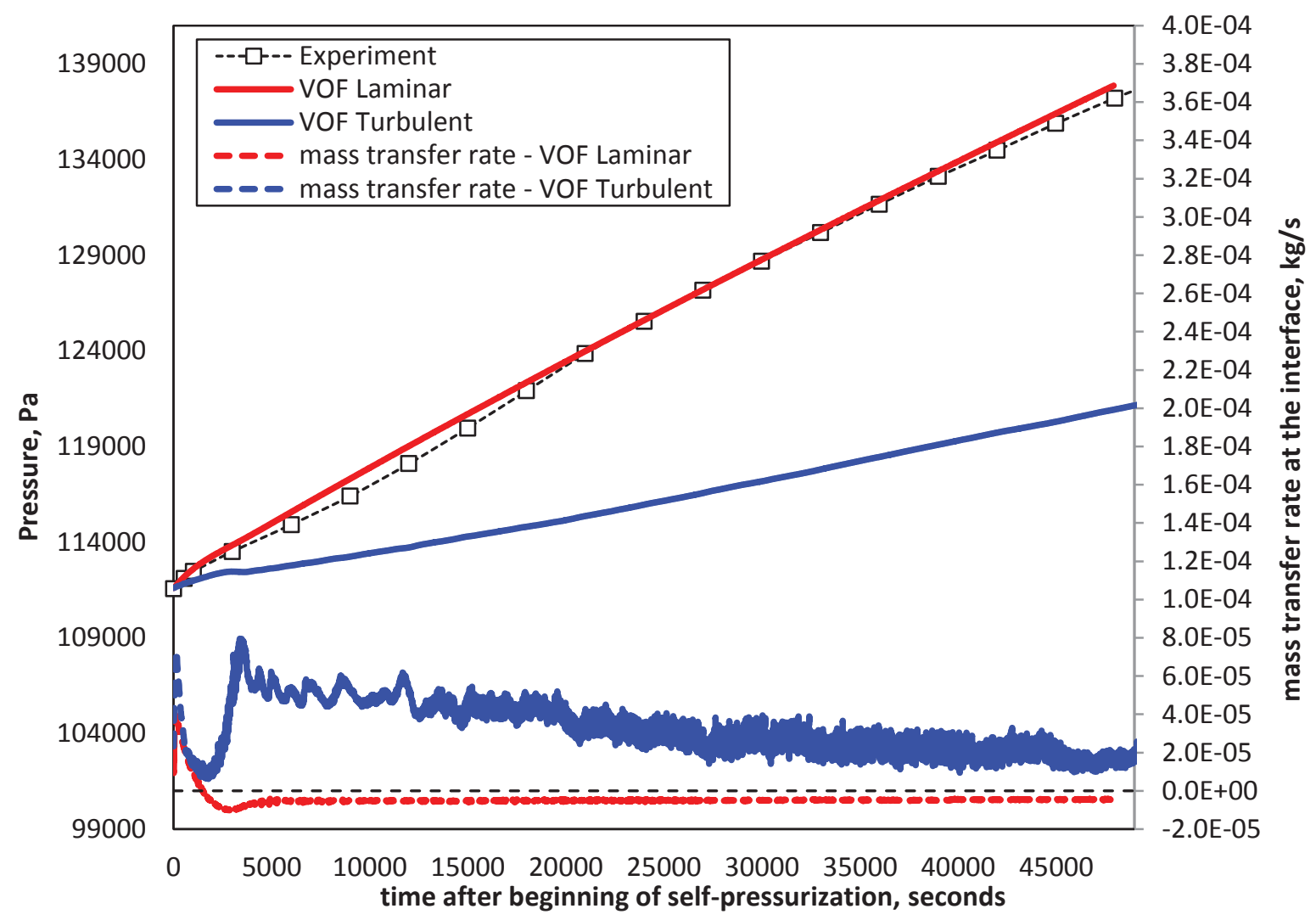

Figure 3: Pressure and interfacial mass transfer rate (positive values represent evaporation) evolutions in the tank during self-pressurization of MHTB tank (50\% fill ratio): Effect of turbulence modeling with the VOF model

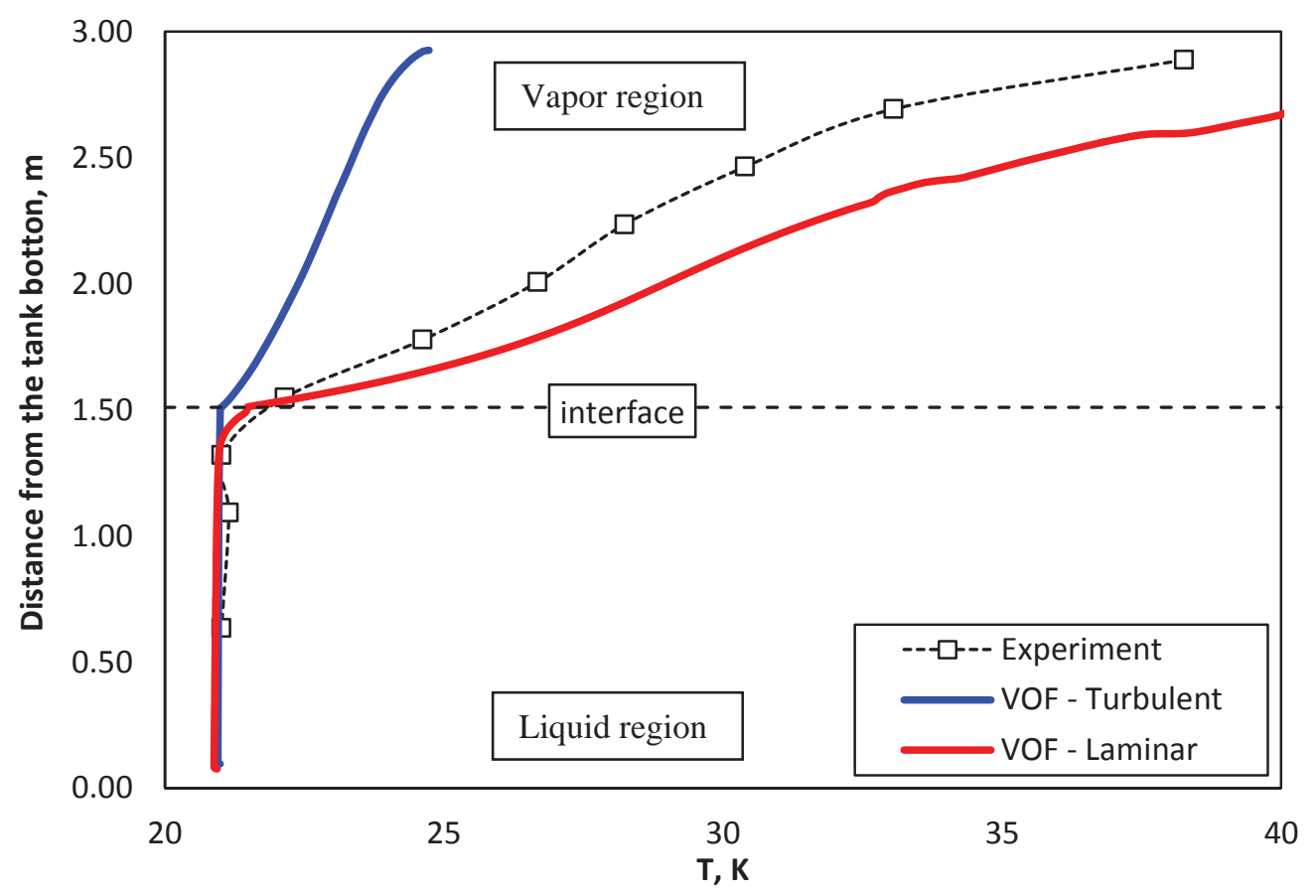

Figure 4: Comparison between laminar and turbulent VOF cases (50\% fill ratio): Temperatures along the vertical rake ( $0.74168 \mathrm{~m}$ off the tank centerline) at the end of tank self-pressurization 


\section{VOF Laminar}

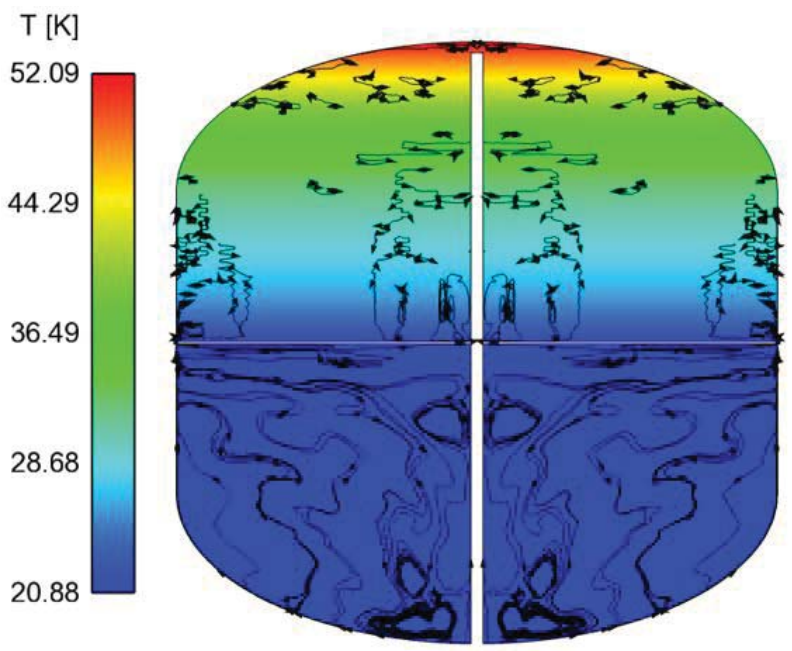

VOF Turbulent

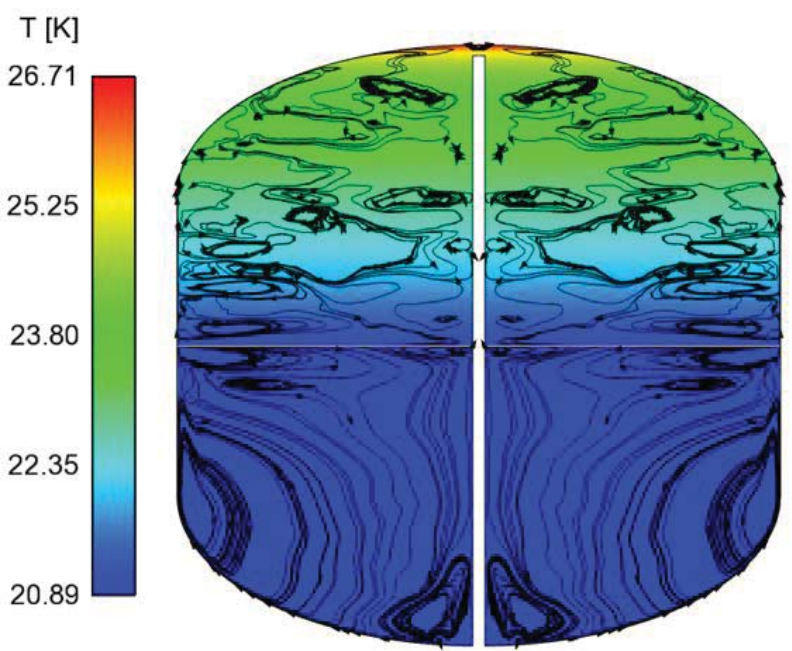

Figure 5: Comparison between laminar and turbulent VOF cases (50\% fill ratio): Tank temperature field and streamlines at the end of tank self-pressurization

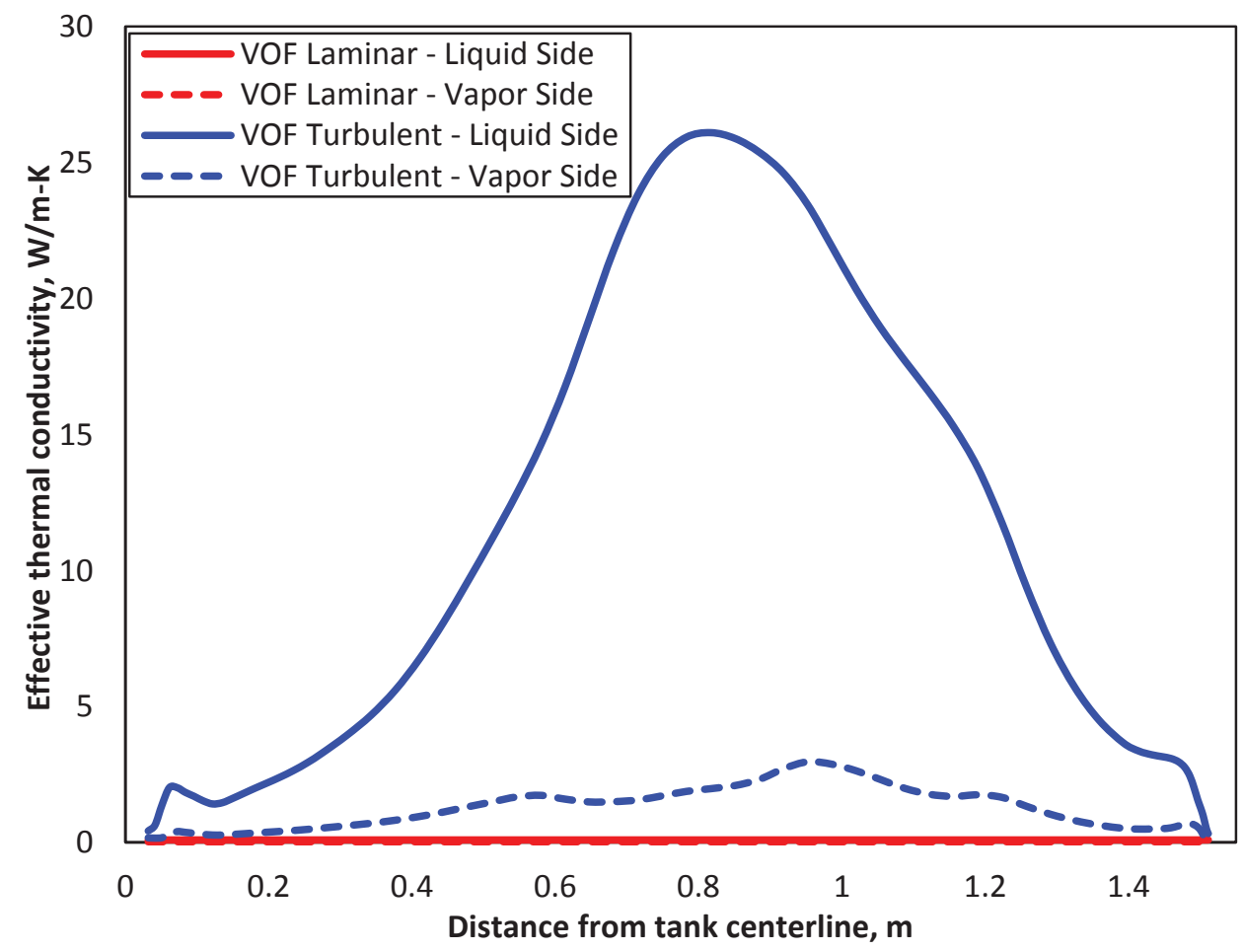

Figure 6: Comparison between laminar and turbulent VOF cases (50\% fill ratio): Effective thermal conductivity plotted along the interface at the end of tank self-pressurization 


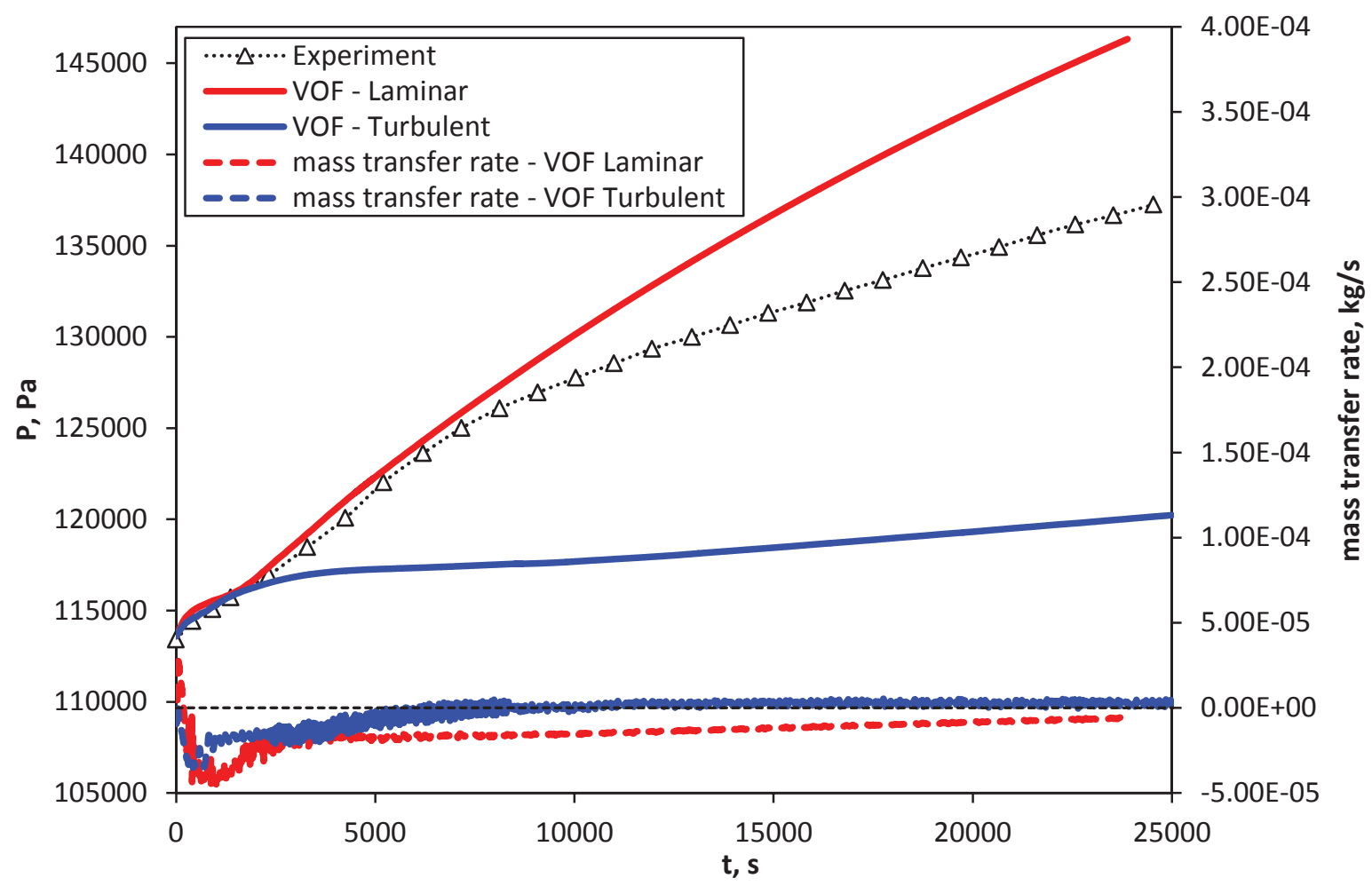

Figure 7: Pressure and interfacial mass transfer rate (positive in case of evaporation) evolutions in the tank during self-pressurization of MHTB tank (90\% fill ratio): Effect of turbulence modeling with the VOF model

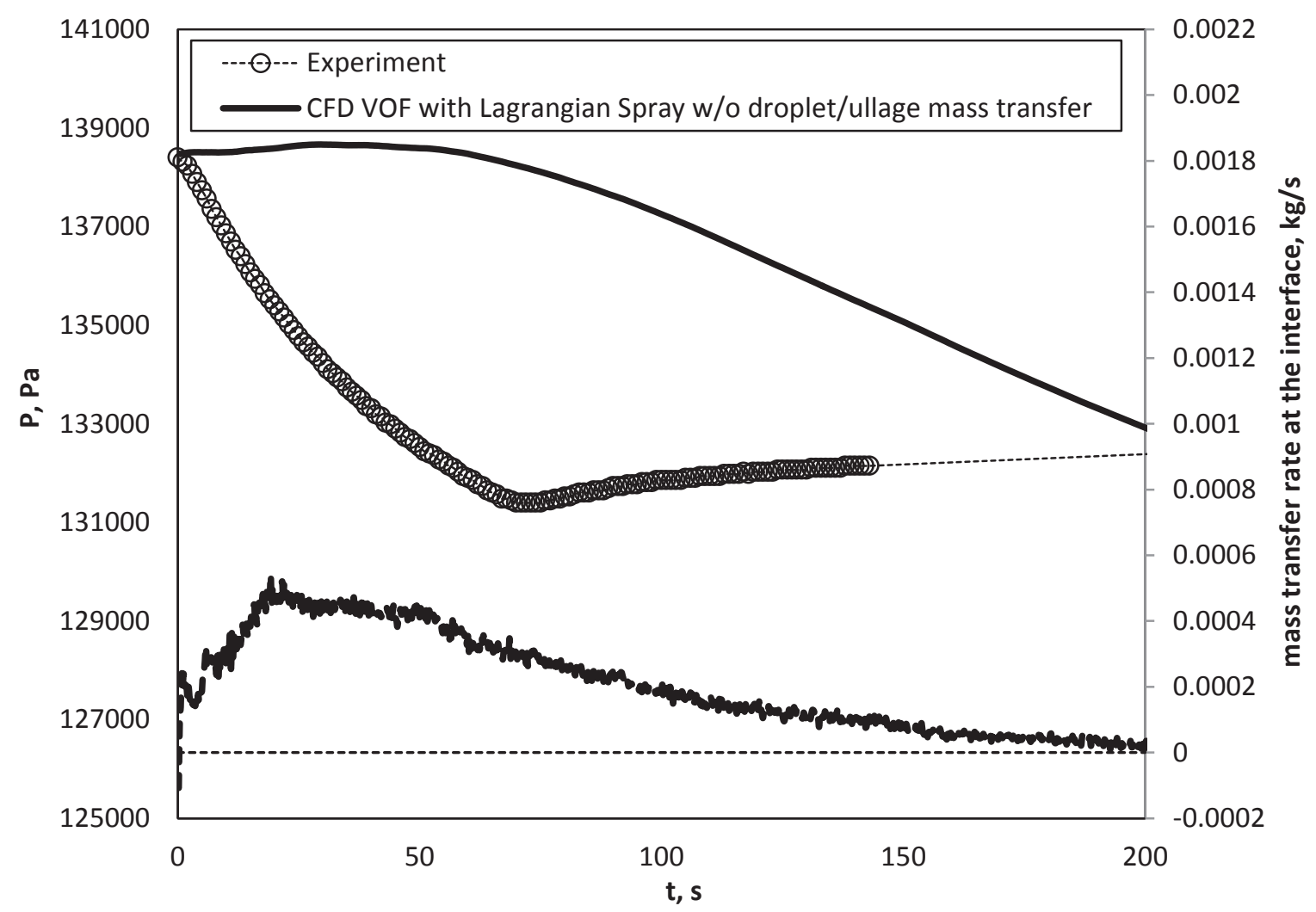

Figure 8: Pressure and interfacial mass transfer rate (positive in case of evaporation) evolutions in the tank during spray cooling of MHTB tank (90\% fill ratio)

American Institute of Aeronautics and Astronautics 

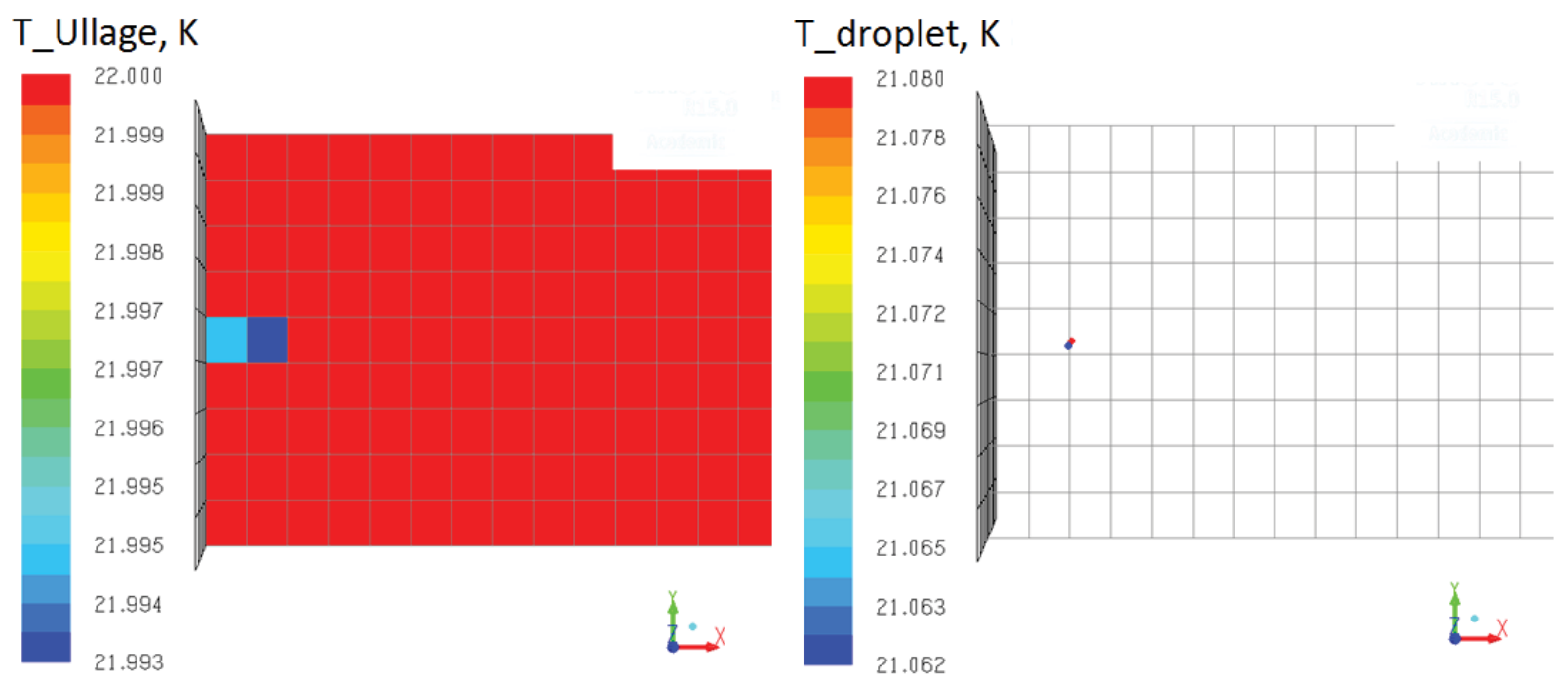

Figure 9: Cell by cell analysis of the droplet/ullage condensation test case ran for 10 time steps with only two droplets injected at the first time step $(\Delta t=0.0001 \mathrm{~s})$

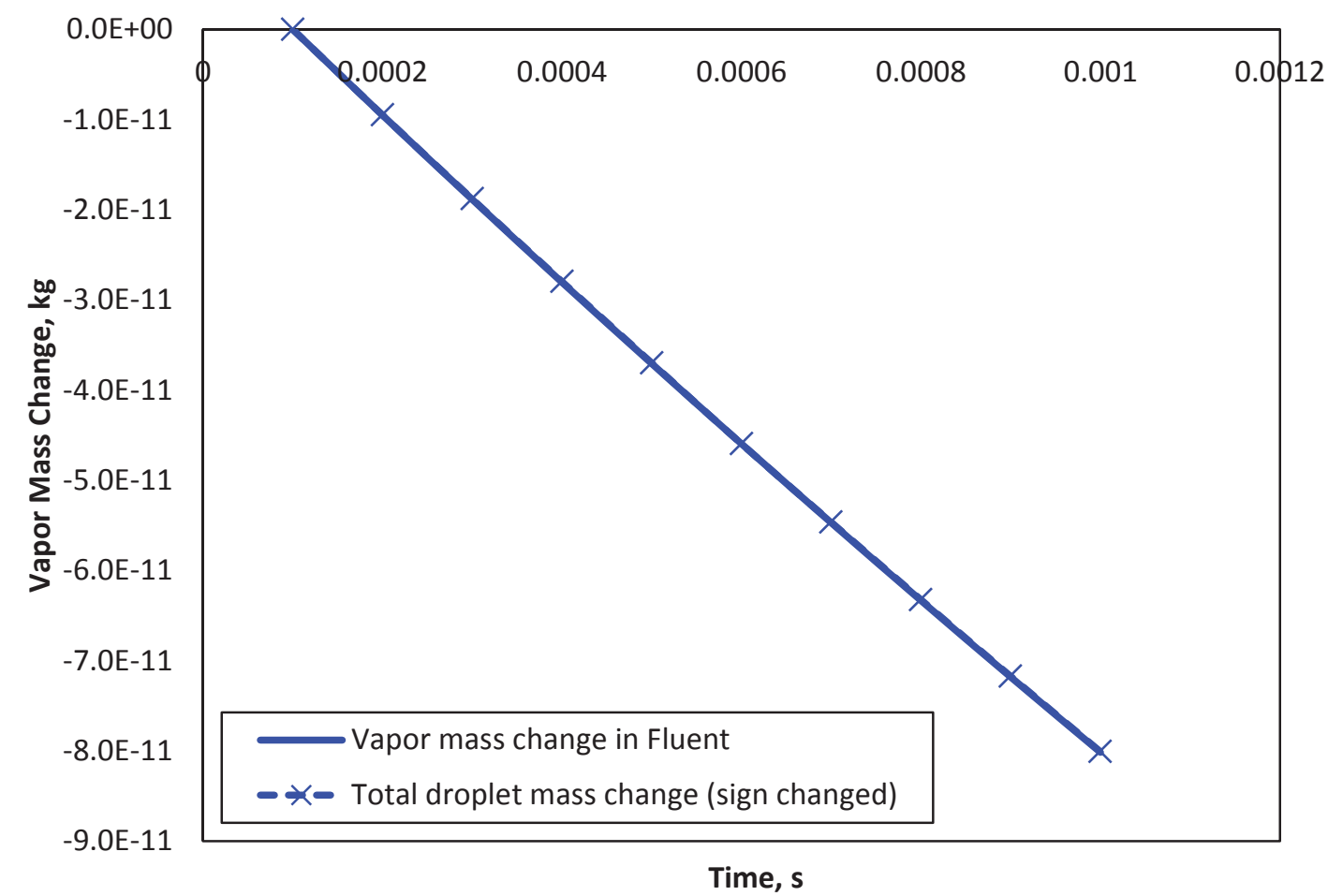

Figure 10: Comparison between vapor mass change in Fluent and total droplet mass change in the subroutine (sign changed) during 10 time steps 


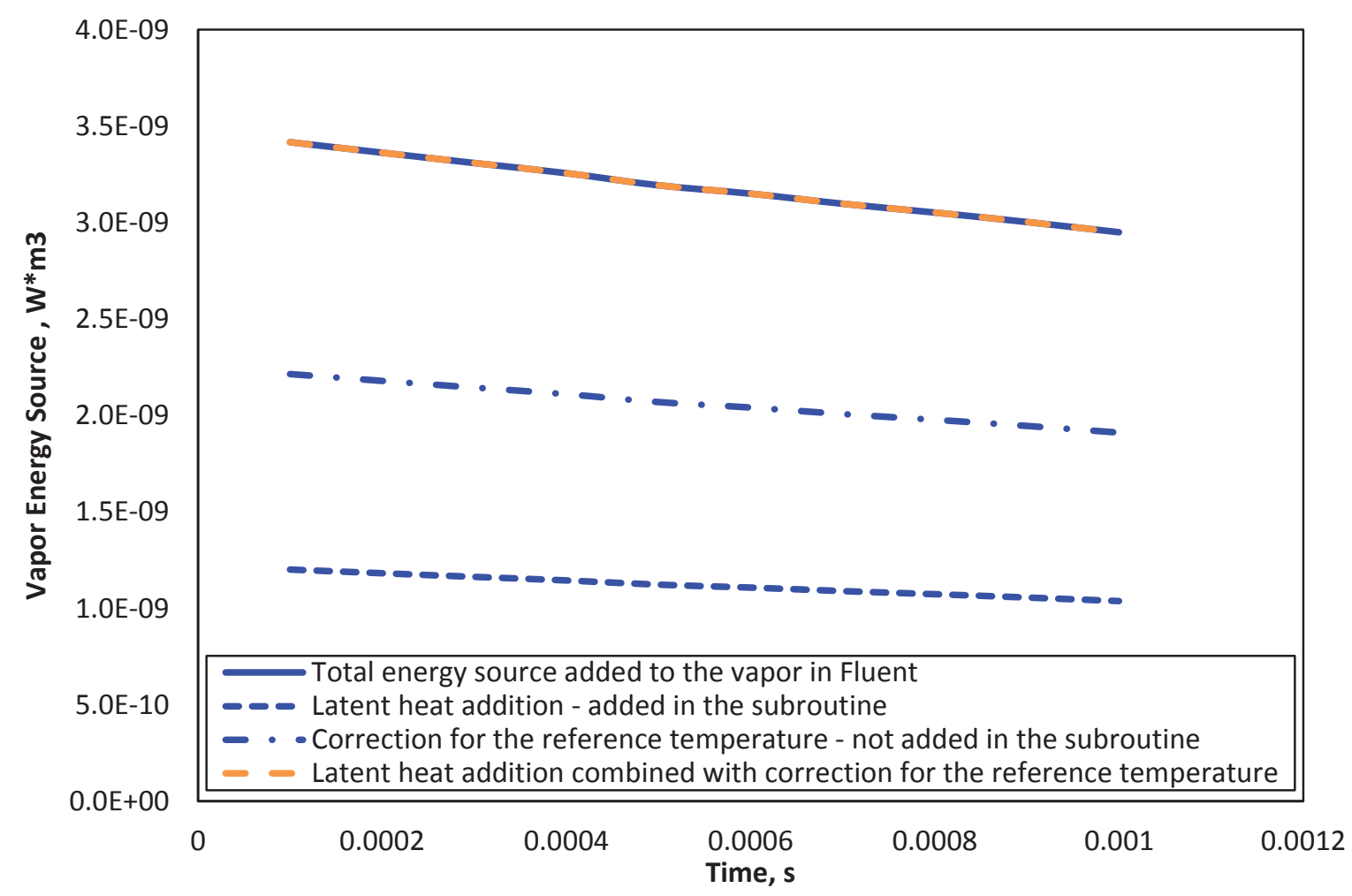

Figure 11: Analysis of the enthalpy source added to the vapor due to condensation on the droplets during 10 time steps
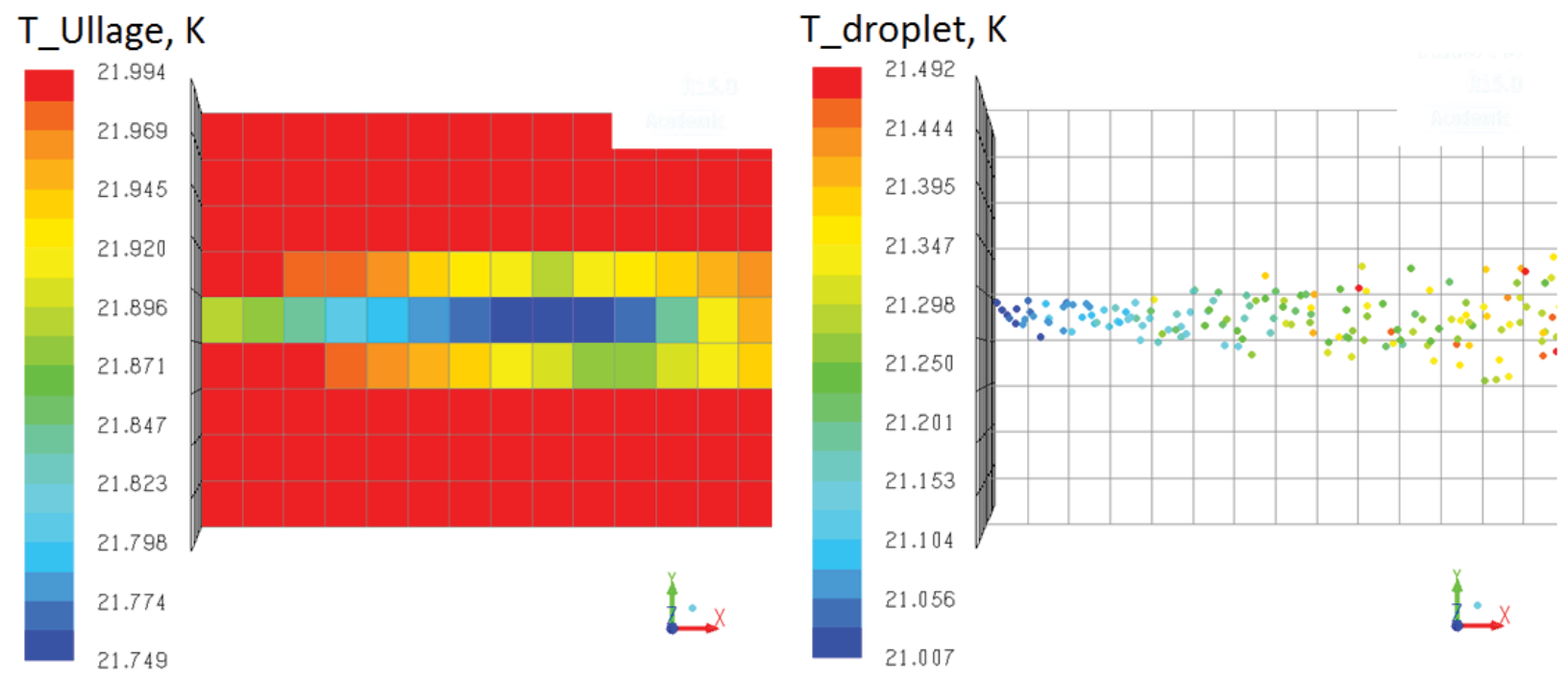

Figure 12: Cell by cell analysis of the droplet/ullage condensation test case ran for 100 time steps with two droplets injected every time step $(\Delta \mathrm{t}=0.0001 \mathrm{~s})$ 


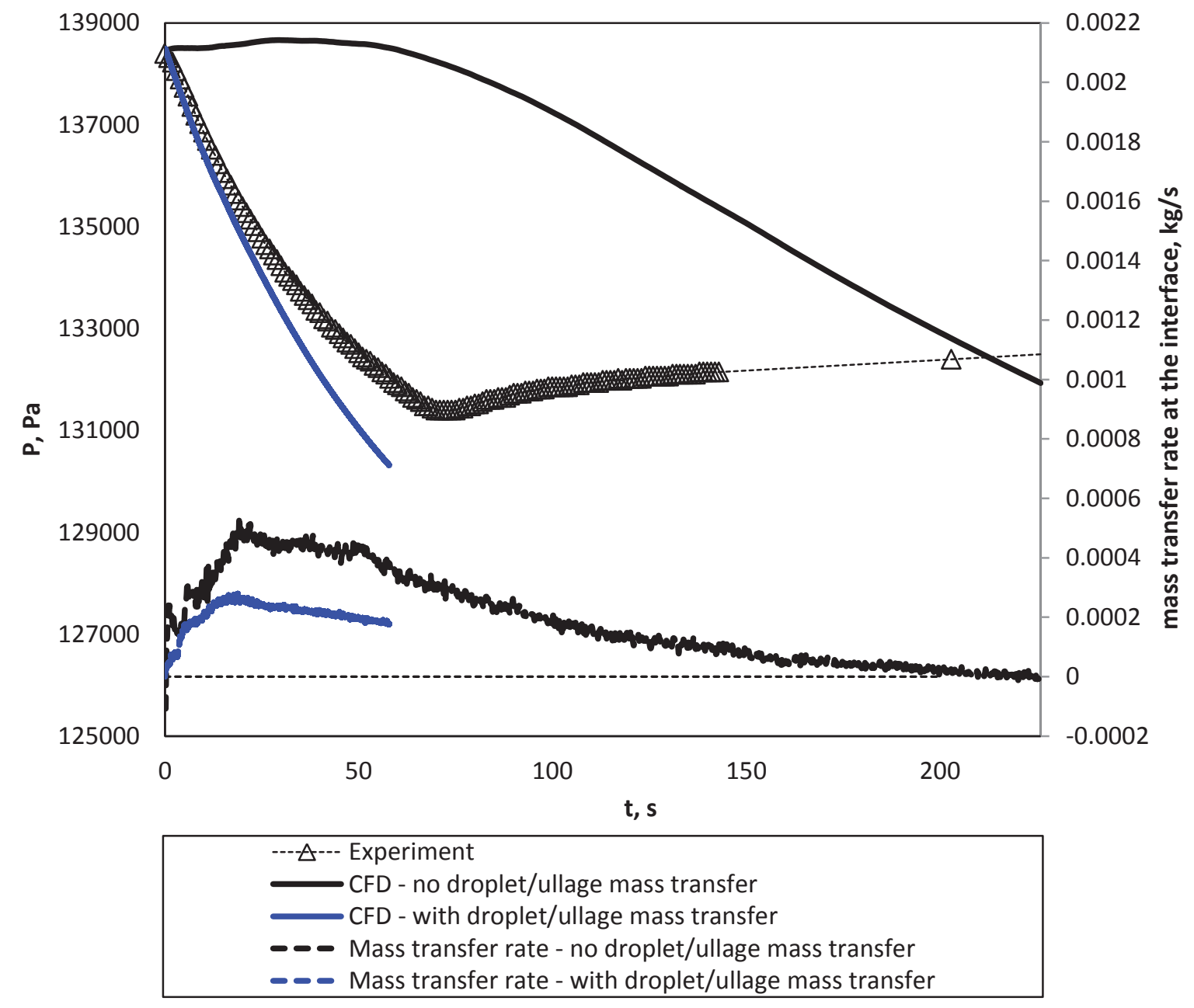

Figure 13: Pressure and interfacial mass transfer rate (positive in case of evaporation) evolutions in the tank during spray cooling of MHTB tank (90\% fill ratio) - results of the model with droplet/ullage mass transfer added 
T_droplet, K
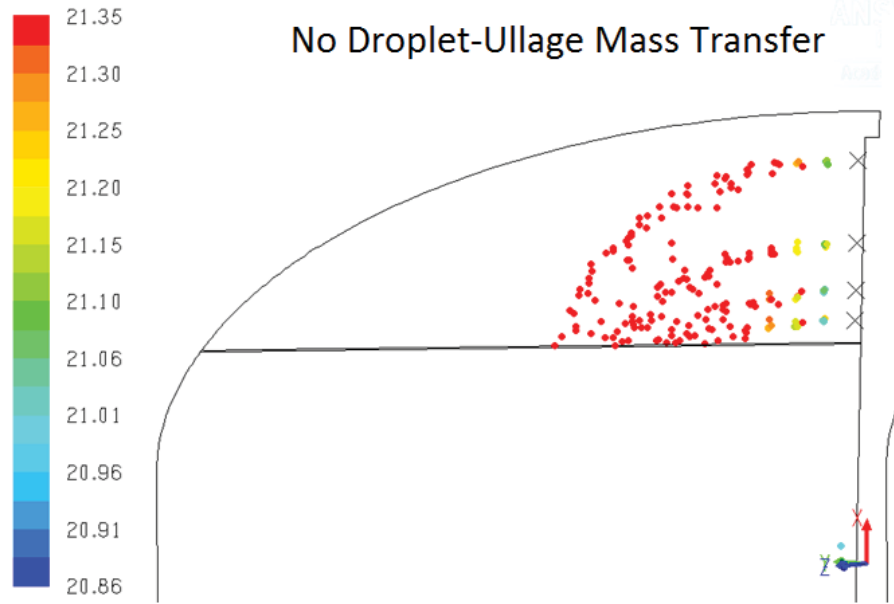

With Droplet-Ullage Mass Transfer

T_Ullage, $\mathrm{K}$

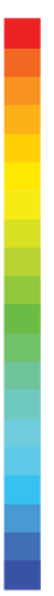

27.59

26.92

26.24

25.56

24.89

24.21

23.53

22.86

22.18

21.51

20.83

$\mathrm{V}, \mathrm{m} / \mathrm{s}$
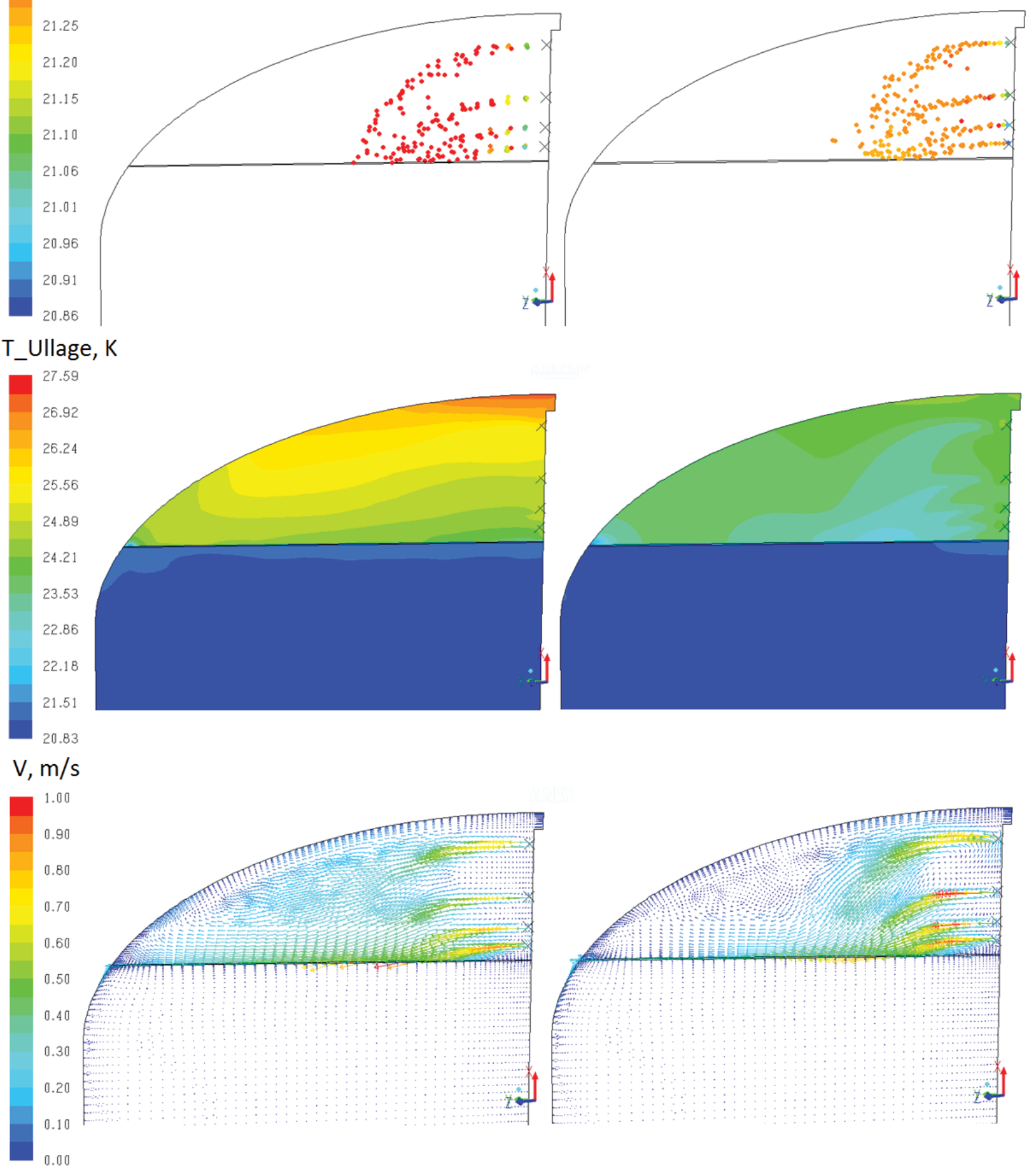

Figure 14: Vapor and droplet temperatures and flow field in the MHTB tank after 50 seconds of spray cooling (90\% fill ratio) - comparison between the models with and without droplet/ullage mass transfer 